\title{
Development of Online Based Smart House Renting Web Application
}

\author{
Dipta Voumick, Prince Deb, Sourav Sutradhar, Mohammad Monirujjaman Khan \\ Department of Electrical and Computer Engineering, North South University, Dhaka, Bangladesh \\ Email:dipta.voumick@northsouth.edu,prince.deb@northsouth.edu, sourav.sutradhar@northsouth.edu, \\ monirujjman.khan@nortsouth.edu
}

How to cite this paper: Voumick, D., Deb, P., Sutradhar, S. and Khan, M.M. (2021) Development of Online Based Smart House Renting Web Application. Journal of Software Engineering and Applications, 14, 312-328. https://doi.org/10.4236/jsea.2021.147019

Received: June 10, 2021

Accepted: July 19, 2021

Published: July 22, 2021

Copyright $\odot 2021$ by author(s) and Scientific Research Publishing Inc. This work is licensed under the Creative Commons Attribution International License (CC BY 4.0).

http://creativecommons.org/licenses/by/4.0/

\section{Abstract}

The house rental issue is one of the elemental parts of society. Nowadays, it is extremely difficult to find suitable accommodation in city areas if people search for it physically. On the other hand, the land owner also needs to rent the house. It can be difficult to find tenants just to hang a lease sign on a building, and as a result, they lose money. An online common platform can play a vital role in this case. The purpose of the study is to develop a common web-based online platform for both tenants and house owners so that both tenants and landowners will mutually benefit from the system. This paper presents the development of web applications for the people of Bangladesh where both house owners and tenants can register and tenants can have houses for rent via sophisticated contact with the house owner. In this paper, a common online-based smart house rental web application has been developed both for tenants and for house owners. This web application is very user-friendly, efficient and it has got many unique features that are not offered by other currently available house rental websites here in Bangladesh. Tenants can register using their phone number, store information about their identity, search for available houses, send messages to house owners, and choose a suitable house using developed web applications. House owners can also register for the system, which will manually verify and authenticate the knowledge provided by the house owner can view a tenant's information history whenever a tenant makes contact through text and supply house-related information accordingly. The proposed online smart house system has been tested and validated. It works very efficiently with many features. The application provided faster and improved opportunities to get houses, as well as ensuring the availability of houses for rent in the greatest number of areas. The system will help to spread trustworthy services nationwide and supply users with the chance to speak and improve the house rent in Bangladesh. Because it has many smart features, this developed online smart house rental 
web application will make it very easy for tenants to find a house to rent. House owners, on the other hand, can easily rent out their properties.

\section{Keywords}

Web Application, Online Platform, House Renting, Smart, Security, Advertise, Network, Remote Interaction

\section{Introduction}

Development of houses for rent has become an important factor in modern society. This chapter will provide a brief understanding of the background of the study, definition of the project problem statement, its objectives, scopes, project justification, project deliverables and project budget and schedule. Housing has central importance to quality of life with considerable economic, social, cultural and personal significance. Though a country's national prosperity is usually measured in economic terms, increasing wealth is of diminished value unless all can share its benefits and if the growing wealth is not used to redress growing social deficiencies, one of which is housing [1].

Housing plays a huge role in revitalizing economic growth in any country, with shelter being among the key indicators of development. Most families choose to rent houses based on their income and family situations. Unfortunately, there may not be enough good quality rental housing for these families. The demand for rental houses is extremely high and more rental houses need to be put in place. Developing rental houses has numerous advantages, particularly for landlords, who can increase their profits through the rent paid by tenants. The increased number of tenants and landlords complicates management, especially for landlords who lose large sums of money to tenants who do not pay their rent. The above statement gives a clear declaration as to why rental house management system needs to develop [2].

Whether you are tired of all the existing ready flat buy sale portal, or in quest of a flat for sale in Bangladesh, let the most noted online property selling site in Bangladesh, is recommended by experts and developers. According to the Bangladesh Labor Force Survey 2016-17, around 44.0 percent of dwelling houses in urban areas of the country are rented while the ratio is only 3.0 per cent in rural areas. Again, as estimated by the Bangladesh Bureau of Statistics (BBS), housing and house rent make up 17.25 per cent of monthly household consumption expenditure. By adding 5.0 per cent of total spending on light and fuel to this, monthly housing related spending becomes almost one-fourth of the total spending of a family [3].

People come to the city from all over the country to live the life they want. Also, people want money and big cities are the platforms for making money. Everyone tries to do business or get a job with a good salary. Now the point is, they come to cities where they have their own place to live. So, everyone tries to 
get a house for rent. Also, students from all districts come to Dhaka and other big cities to pursue higher education. 97\% of students are bachelors and they need a house to live in. But the main problem is that getting a house for rent is lengthy and it takes a long time to be processed [4].

Table 1 depicts Dhaka's population growth rate over the last ten years. Table 2 contains the data population from all the big cities.

Components of a basic but decent life for a family, moving from the cost of a basic but decent life to a net living wage, and moving from a net living wage to a gross living wage are given below in Figure 1.

Table 1. Dhaka's population growth rate over 10 years.

\begin{tabular}{ccc}
\hline \multicolumn{3}{c}{ Dhaka-Historical Population Data } \\
\hline Year & Population & Growth Rate \\
\hline 2020 & $21,006,000$ & $3.56 \%$ \\
2019 & $20,284,000$ & $3.61 \%$ \\
2018 & $19,578,000$ & $3.62 \%$ \\
2017 & $18,894,000$ & $3.62 \%$ \\
2016 & $18,234,000$ & $3.62 \%$ \\
2015 & $17,597,000$ & $3.62 \%$ \\
2014 & $16,982,000$ & $3.62 \%$ \\
2013 & $16,389,000$ & $3.62 \%$ \\
2012 & $15,816,000$ & $3.62 \%$ \\
2011 & $15,264,000$ & $3.62 \%$ \\
2010 & $14,731,000$ & $3.62 \%$ \\
\hline
\end{tabular}

Table 2. The data of population from all the big cities.

\begin{tabular}{cc}
\hline & Other Cities in Bangladesh \\
\hline City Name & Population \\
\hline Dhaka & $21,006,000$ \\
Chittagong & 954,000 \\
Khulna & 908,000 \\
Rajshahi & 852,000 \\
Sylhet & 775,000 \\
Bogra & 589,000 \\
Comilla & 484,000 \\
Barishal & 482,000 \\
Rupganj & 460,000 \\
Mymensing & 460,000 \\
Rangpur & 407,000 \\
\hline
\end{tabular}




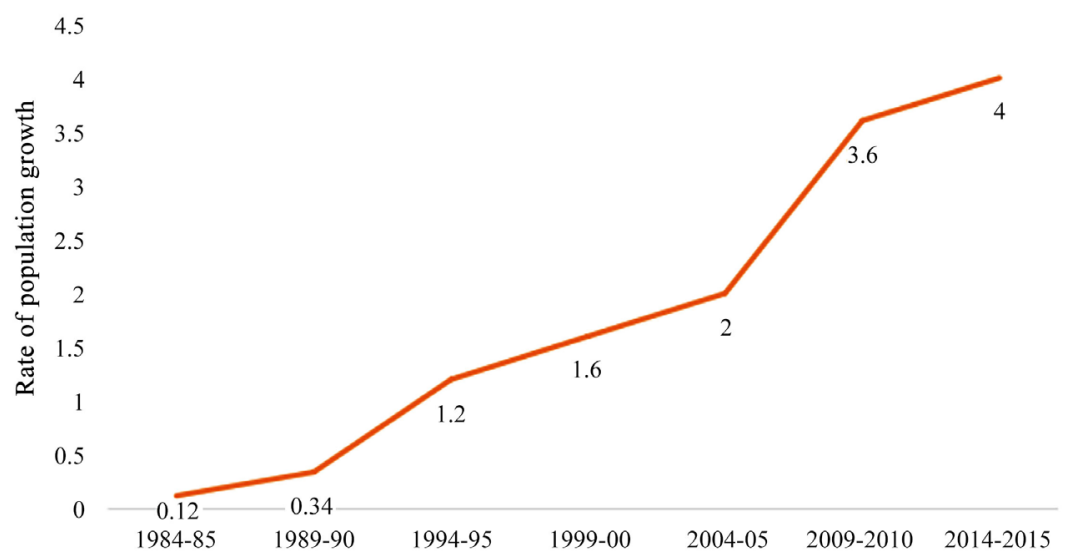

Figure 1. Graph showing the population growth rate from 1984-85 to 2014-15.

\section{Existing Works}

For almost 17 years, "bdHousing.com" has held the dominating position of offering a traditional and well-accepted stage for property owners to promote their assets for rent or sale, as well as allowing property seekers to discover their dream house. As a result, it is now known as Bangladesh's largest online property selling website [5].

"Renthome" is an internet marketplace that assists individuals in finding land, a cheap home, or business space. Their goal is to provide our valued clients with the most up-to-date marketing information and make it as easy as possible for them to contact brokers, developers, and landlords. As Bangladesh's leading ready-to-buy-and-sell platform, they've designed their system to provide you with as much information on your preferred property as possible at any moment [6].

The famous Bangladeshi largest market place "Bikroy.com" has a partial section for house rent or buy-sell. Since then, the system has worked as a place to buy and sell used items.

But there are some problems found there. These reviewed systems do not have the proper location tracing with an updated map location system, and a live end to end secured chatting system has not been introduced into these existing systems.

An online platform with an economical strong hold and spectacular interface all covered with an up-to-date security protocol. Financially stable (a scale of financial background) people can join here and get a suitable house to live. On the other hand, people who have properly checked their background will want to sell or rent their houses [7] [8].

As, reviewed some similar systems of the basic project plan, the realization is that, online based house rent service needs much more up gradation in Bangladesh. An internet-tech friendly system which will be more updated and resourceful in many ways will be built by us. The system will be built based on new technology and will update the system in a time cycle. This system will provide the solution of home rent problems in some unique ways. Here, a tenant can directly contact with a house lord via chatting system which will be a feature in the 
box. Our main target will be helping the house buyer/tenant and house owner/house lords to connect with each other. There will be no middle man in between a deal of house because buyer and seller will connect directly with one another. Business will be safe. Our main priority will be a friendly environment with user's security and privacy in a maximum observation [9].

Financially stable peoples will find a great comfort here. Also, people with a decent background and interested in business of house rent are the part of this system [10].

Nowadays, people are interested in easy-to-handle systems with a lot of information in it. We will build our system much interesting for the people. Also, it has found that Google maps are not properly used in the system for house rent built by other professionals. In this system, Google API will be bought and merge it in the system. It will show the proper house locations in the maps [11].

Financially stable people will find great comfort here. This system also includes people with a good background who are interested in the house-renting business [10]. Nowadays, people are interested in easy-to-handle systems with a lot of information in them. We will build our system much more interesting for people. Also, it has found that Google maps are not properly used in the system for house rent built by other professionals. In this system, Google API will be bought and merge it in the system. It will show the proper house locations on the maps [11].

\section{Methodology}

The term methodology means the technique and procedure of the system adopted for conducting a research study. It shows how data will be collected and the tools for collecting data, system methodology, the proposed system input and output, users and systems development tools. System development is a technique that is used to show how the proposed system will be developed. In this case, the methodology used will be a waterfall model. It is included in the stages that the developer will use when developing the system [12] [13].

It is a sequential model and the name is waterfall. The developer must to finish with one stage before going to the next stage. It contains the feasibility study, analysis phase, design phase, coding phase, testing phase, implementation phase and finally the maintenance phase. It is a simple model and easy to use and understand to make a system. With waterfall development-based methodologies, the analysts and users proceed to work sequentially from one phase to the next phase. The deliverables from each and every phase are voluminous and are presented to the project sponsor for approval as the project moves from phase to phase. Once the client has approved the phase, the next phase begins with database design. It is at this stage that we will identify any faults before moving to the next stage. The output of this stage is the design specification which is used in the next stage of implementation [14] [15].

Figure 2 shows the software development cycle. Basically, you design the sys- 
tem, code it and test it. When an error is found, it must be determined whether the error is a design error or not. Coding errors can quickly be fixed, but design errors may take longer.

\subsection{Waterfall Model}

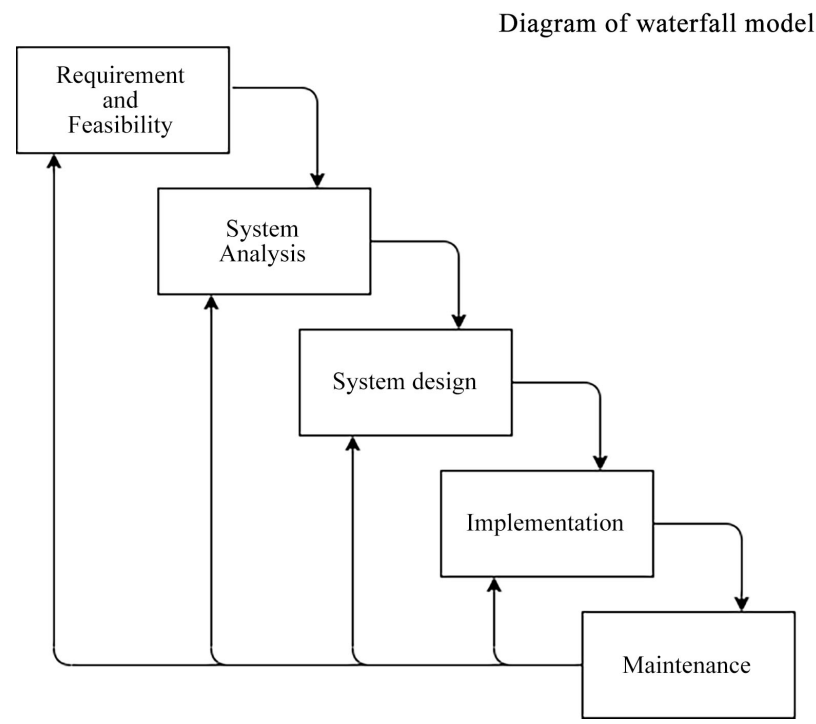

Figure 2. Block diagram of waterfall model.

\subsection{Software Design}

This system is designed to be a reference for any person wishing to implement or any person interested in the system of house rent application. Each application's architecture and sub-architecture, their associated interfaces, database schemas, and the motivations behind the chosen design have been described here. Both high-level and low-level designs are included [16]. This work is done by experienced developers who can do reading data flow diagrams (DFDs), control flow diagrams (CFDs), interface designs, and development experience in object-oriented programming and event driven programming [17].

This system includes the following information for the House Rent System; system overview, design considerations, architectural strategies, system architecture, policies and tactics, and detailed system design [18].

The user's requirements document was analyzed for a better understanding of what was required by the system. Ways of implementing these requirements were analyzed. Physical modules of the system were designed and identified the operating environment in which they were to work [19]. The system was a visual-basic system/application. The database is updated each time the administrator adds, deletes or deletes data from the system. This system is dependent on an administrator who has access to the entire system and can view or make changes as needed. It's open and closed for administrators and administrators alike. It is open to extension and closed to modification for owners and tenants. Each owner can login and make an advertisement for his/her house. The entire data 
set is stored in a database, which is managed by an administrator. Tenants can select the desired house by reviewing the advertisement [20]. Basically, the administrator is the monitor of this system. The entire system design is involved in converting software requirements into an architecture that describes its top-level structure, identifies software components, and creates a product. Figure 3 shows the flowchart of total process. The system is based on the waterfall model [21]. The waterfall model is a classical model that is used in the system development life cycle to create a system with a linear and sequential approach [22]. The model is called a waterfall because it progresses systematically from one phase to the next in a downward direction. This model is divided into different phases and the output of one phase is used as the input for the next phase. Every phase has to be completed before the next phase starts and there is no overlapping of the phases.

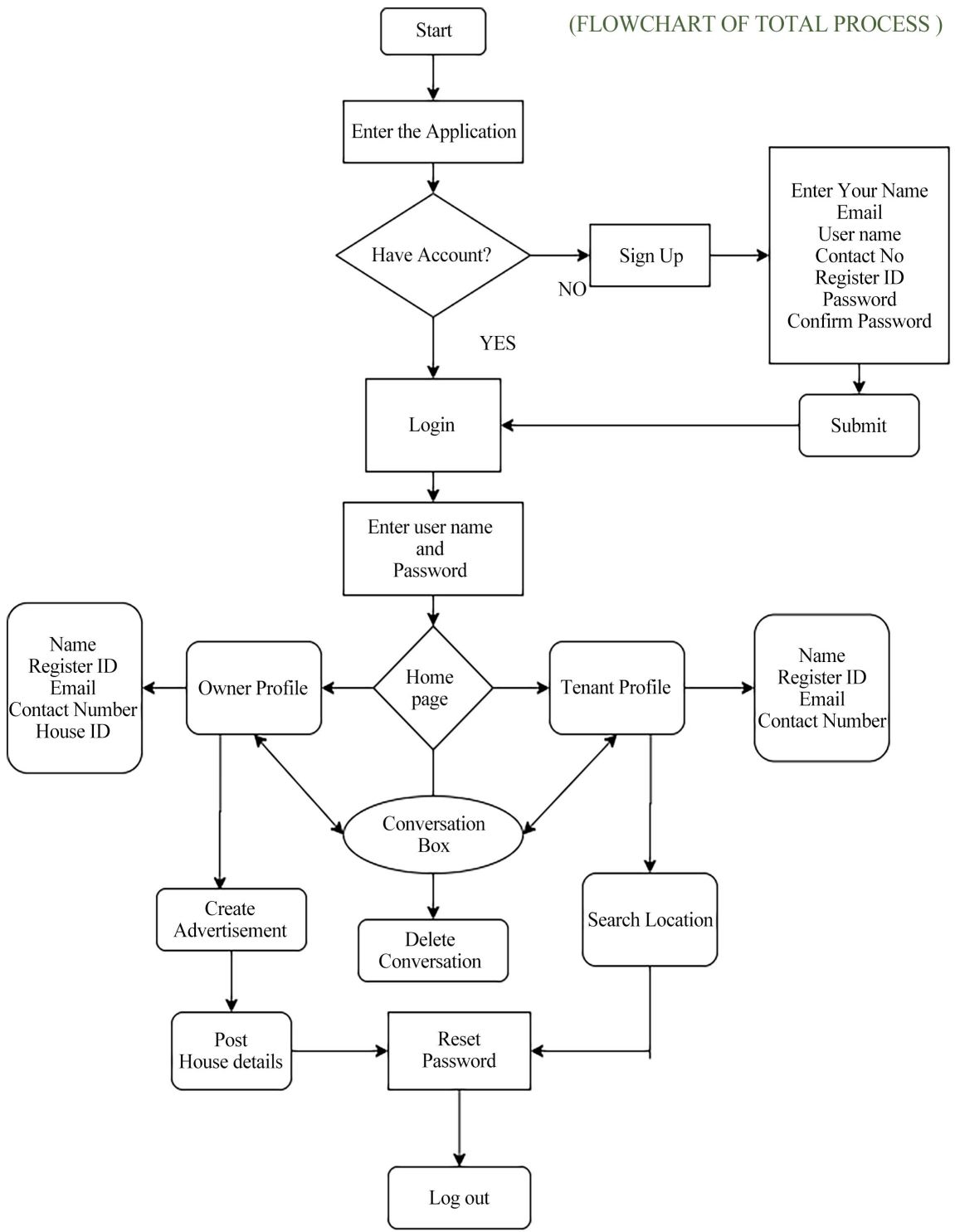

Figure 3. Flowchart of total process. 


\subsection{Technical Tools}

In this system, MySQL used for create and edit the database. Sublime text is prime text editor for all the codes. PHP, JAVA, and HTML are the languages that write all the codes. LARAVEL was used for some secure feature designs. CSS, JAVASCRIPT and AJAX were used for the frontend design of the system.

MySQL: MySQL Database Service is a fully managed database service to deploy cloud-native applications using the world's most popular open-source database [23].

Java: Java is a class-based, object-oriented programming language that is designed to have as few implementation dependencies as possible.

Laravel: Laravel is a web application framework with expressive, elegant syntax.

PHP: PHP is a general-purpose scripting language especially suited to web development.

HTML: Hypertext Markup Language is the standard markup language for documents designed to be displayed in a web browser. It can be assisted by technologies such as Cascading Style Sheets and scripting languages such as JavaScript [24].

CSS: Cascading Style Sheets is a style sheet language used for describing the presentation of a document written in a markup language such as HTML. CSS is a cornerstone technology of the World Wide Web, alongside HTML and JavaScript.

JavaScript: JavaScript, often abbreviated as JS, is a programming language that conforms to the ECMA Script specification. JavaScript is high-level, often just-in-time compiled, and multi-paradigm [25].

Ajax: Ajax is a set of web development techniques using many web technologies on the client side to create asynchronous web applications. With Ajax, web applications can send and retrieve data from a server asynchronously without interfering with the display and behavior of the existing page [26].

Sublime text: Sublime Text is a shareware cross-platform source code editor with a Python application programming interface (API).

\section{Basic Diagram}

Figure 4 shows the basic diagram of this system. It shows that the admin can control the whole system and also control the database. Owners can advertise their properties with specifics, and tenants can look for places to rent a home. The owner and tenant can also talk to each other using a conversation system. Admin has the full access of database and the system. Modification and monitoring will be done by the admin. Owners and tenants will register in the system and the registration data will be saved in database for further enquiry and verification.

\subsection{Overall Use Case Diagram}

Figure 5 provides the total use case diagram of the system. The system has three 
types of users: admins, owners and tenants. This system can be used by owners and tenants after a successful and verified registration. For admins, the system is open for extension and modification. Total system will be monitored by the admin. For owners or tenant users, it is open for extension and closed for modification. That means owners could post house advertisements and tenants could start a conversation with the owner in a dedicated chat box.

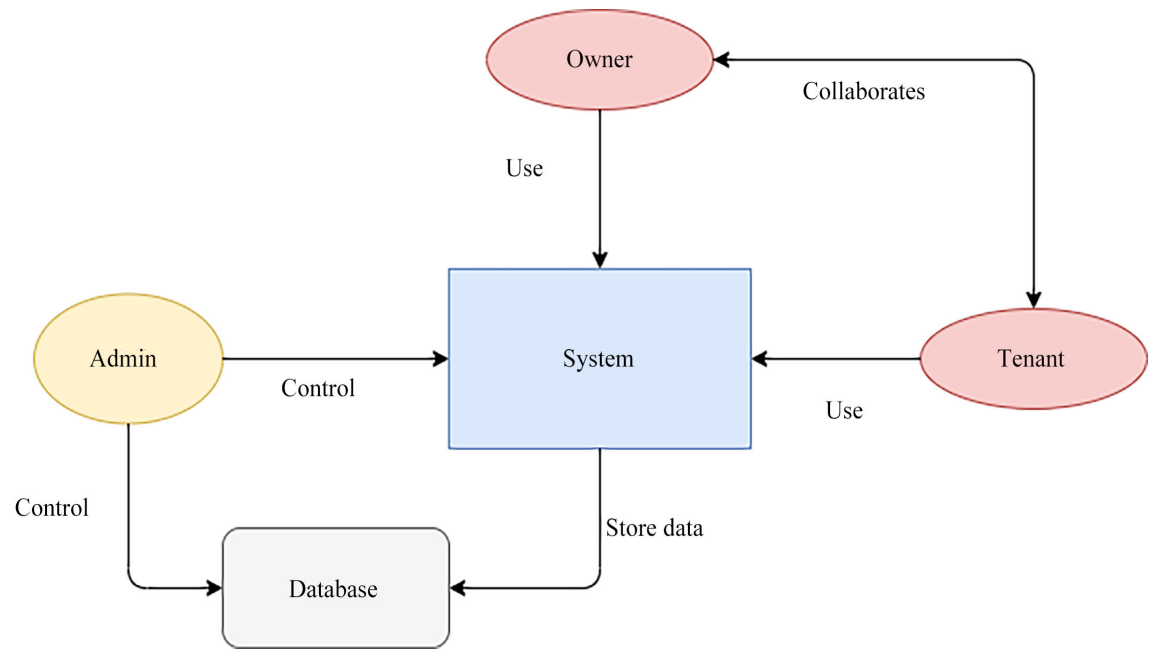

Figure 4. Basic diagram of the system.

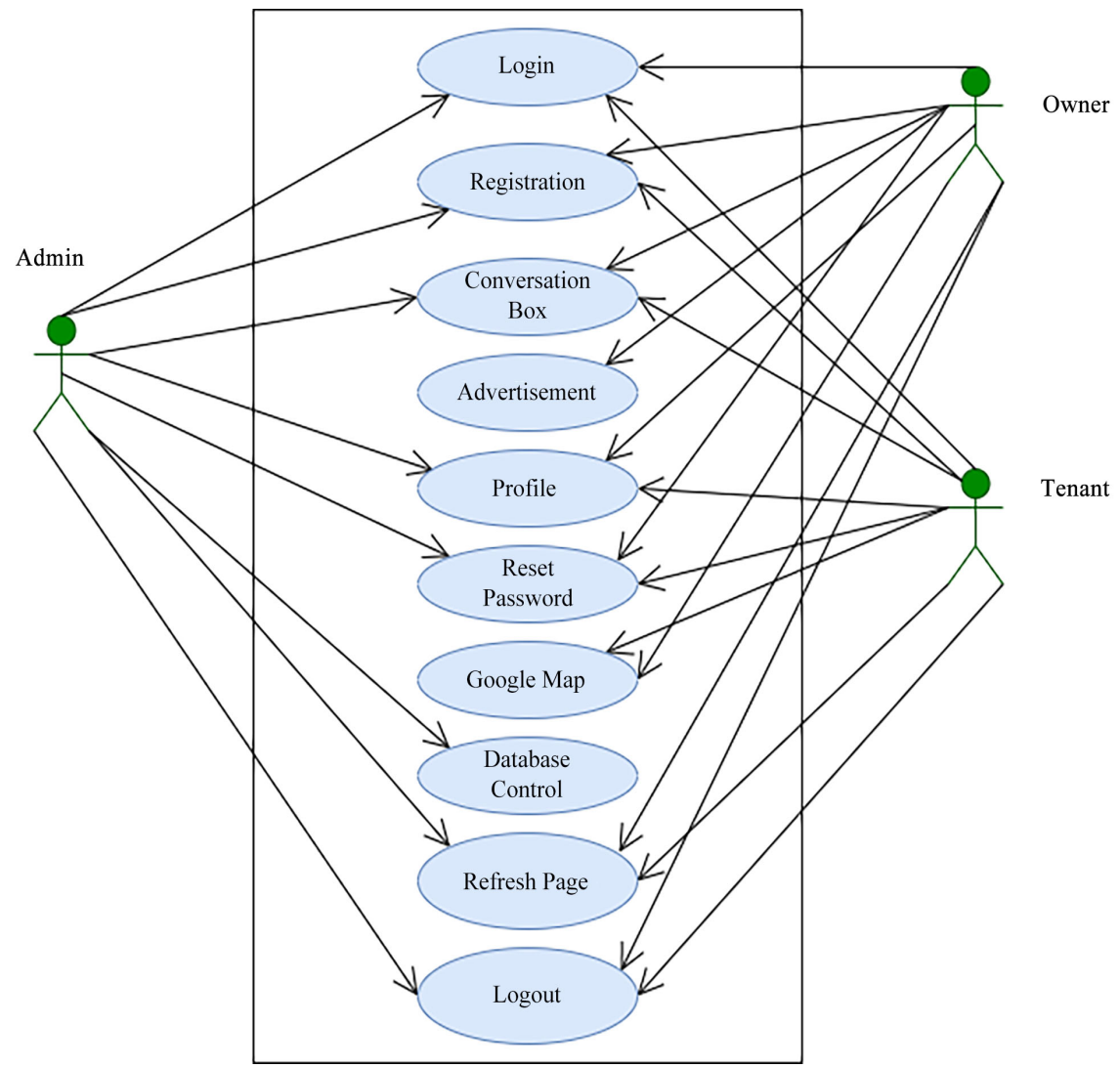

Figure 5. Total use case Diagram of the System. 


\subsection{Admin Use Case Diagram}

Figure 6 contains the admin use case diagram of the system. It shows what types of process in the system are done by an admin. Here, admins can log in to the system after registration. Admin can control the database like delete something or update something from the database. Also, they can see the Google map and, using the conversation system, they can easily contact others. Admin also reset the password and refresh the page.

\subsection{Owner Use Case Diagram}

Figure 7 depicts the system's use case diagram created by the owner. It shows what types of processes in the system are done by an owner. Here, owner can register in the system and log into the system. Also, could initialize a conversation with tenants and could add or delete the advertise of his/her house.

\subsection{Tenant Use Case Diagram}

Figure 8 shows the tenant use case diagram of the system. It shows what types of processes are done by a tenant. Here, tenants can log in to the system after their registration. Tenants can set their own profile and reset the password. Also, contact with others using a conversation system and refresh the page.

\section{Result and Analysis}

In this section, all features of the system are described from the view of a general user.

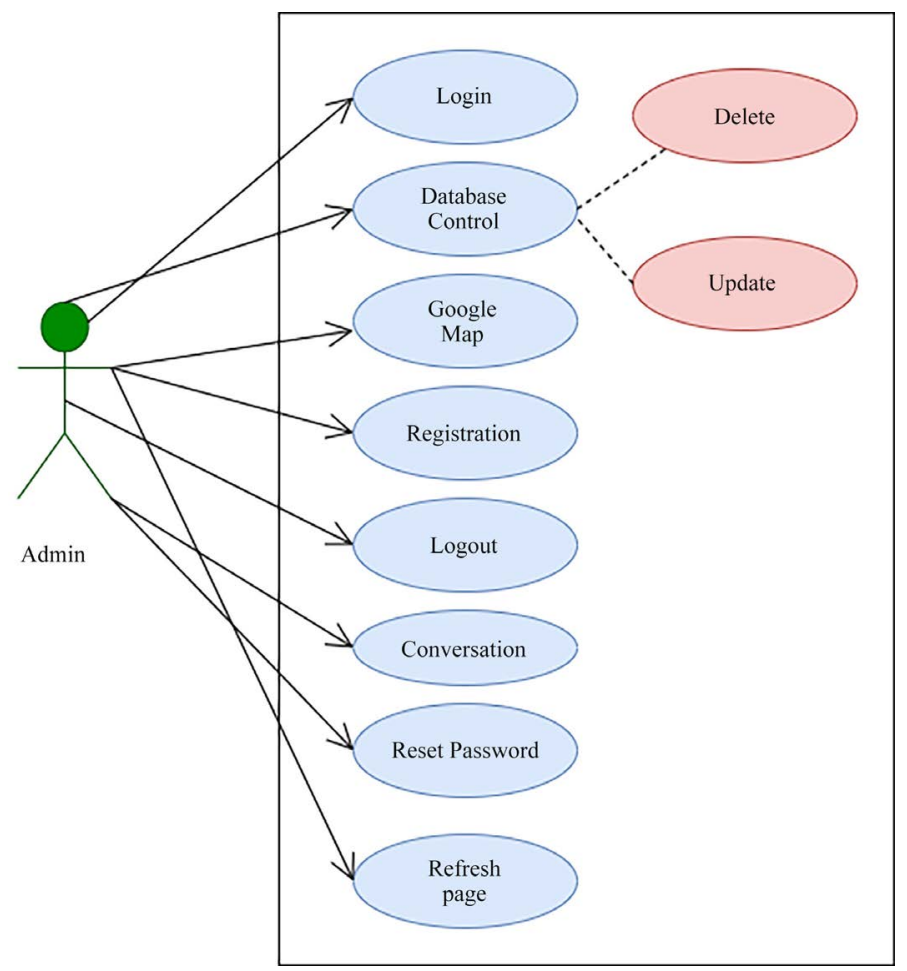

Figure 6. Admin use case Diagram. 


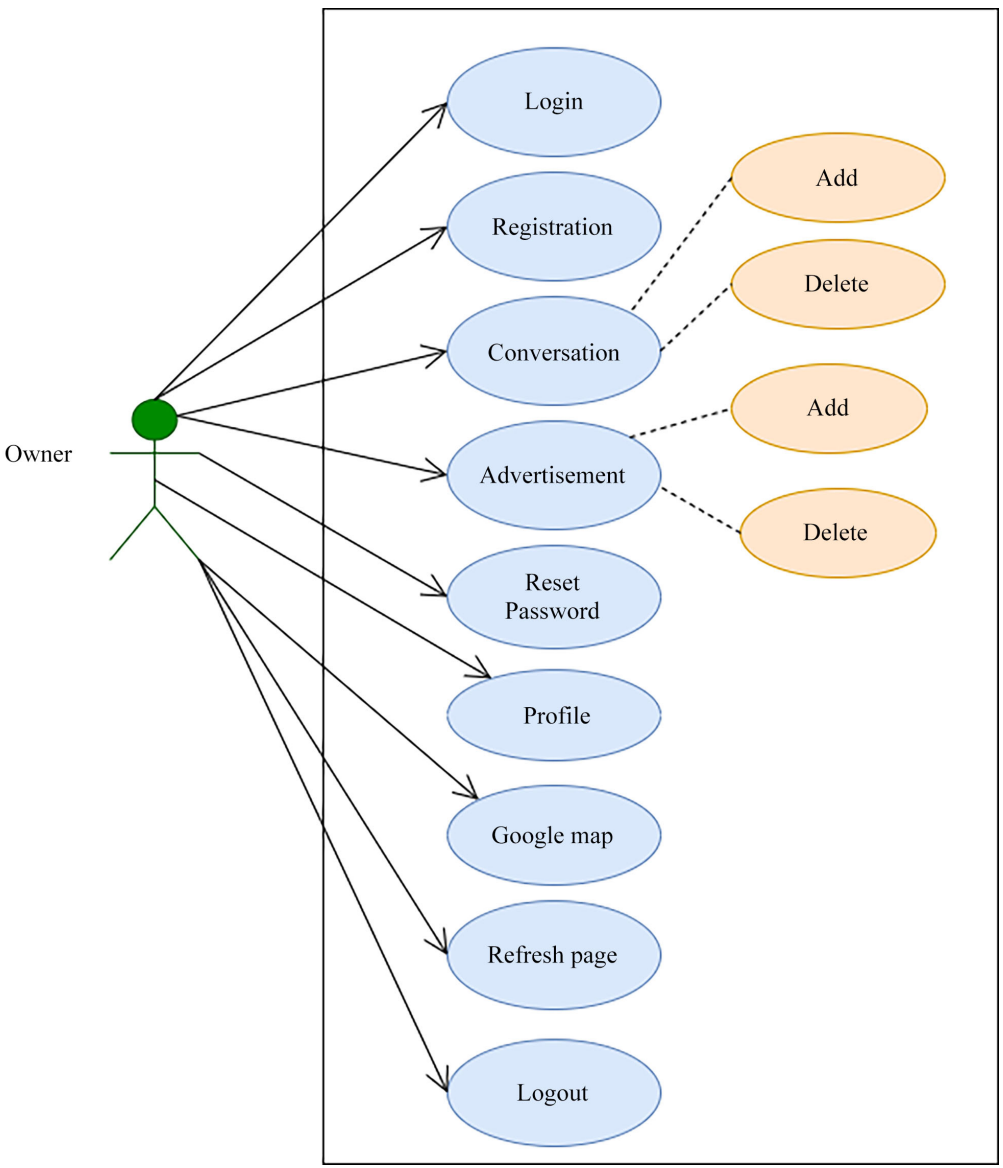

Figure 7. Owner use case diagram.

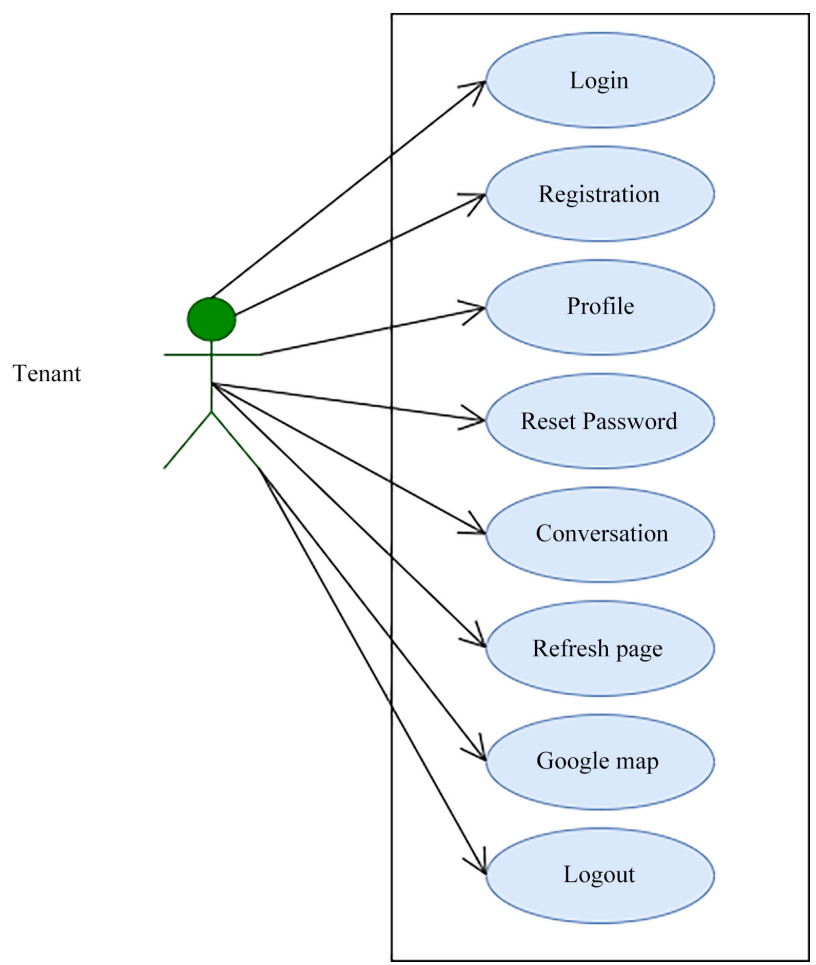

Figure 8. Tenant use case Diagram. 


\subsection{Sign up Page}

Figure 9 shows the registration part. In the registration part, there are 7 columns (Register ID, Name, Username, Email, Contact, Password, Confirm password). Here, the phone number and email must be unique. For registration user have to fill up this page, first of all user give the register ID, then write the full name, username, here email have to be verified email then contact number, password and confirm password. From this page user can reset their information also.

\subsection{Sign in, Creating Post Page}

There is a login page for the system. There are two columns on the login page (username and password). In this system there is also the "creating a post" page. This page is important to the owner. The owner can post information about his home, including photos. The tenant can see this post and contact them to get the house he wants. For admins, this system is open for extension but closed for modification. The admin can delete the post if the owner uploads something that is violent.

\subsection{Owner and Tenant Profile Page}

Figure 10 and Figure 11 depict the profiles of the owner and tenant, respectively. Owners and tenants will be able to store their information here as well. In Figure 10 owner have to fill up this page for set their profile information, first of all owner write the full name, ID, Address, here email have to be verified email then contact number and house id. From this page owner can reset their information also. In Figure 11 tenant have to fill up this page for set their profile information, first of all owner write the full name, ID, Address, contact number and email. Here email have to be verified email. From this page tenant can reset their information also.

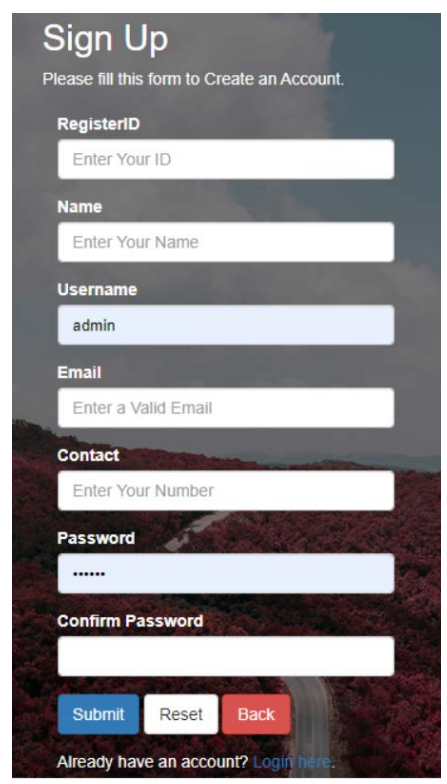

Figure 9. Sign up page. 


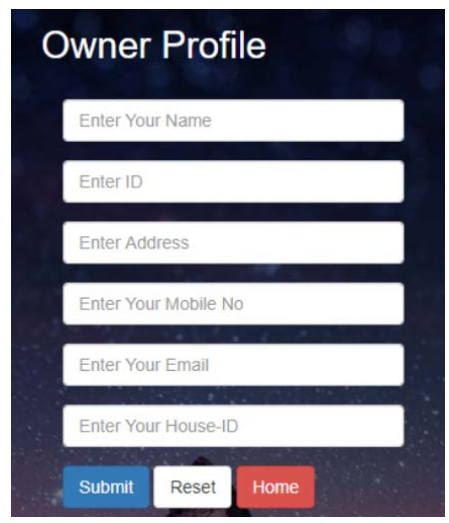

Figure 10. Owner profile page.

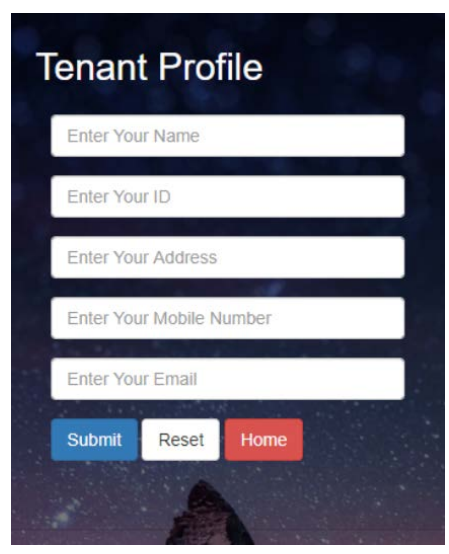

Figure 11. Tenant profile page.

\subsection{Reset Password Page}

There is also the reset password option in the proposed system. A user can change his/her previous password by using this system. The password must be at least 6 characters long and no more than 50 characters long.

\subsection{Conversation System Page}

Figure 12 depicts their application's communication system. A user can send a message and other users can receive it. Here, users first write their name in the first box, then write their opinion in the second box. After that, using the send button, they can easily send the message to another user. Users can also choose to delete the message. This system is open to expansion but not to modification. That is, everyone can see the message and respond to it, but they cannot edit the messages of others.

\subsection{Google Map}

Figure 13 depicts a Google map, which allows users to easily find and track their location. The Google map API key is obtained from Google in order to use the Google map. Google provides free API with some limited features in it. This is the result of Google's development. Users will be able to see the location easily, 
and a tracking location feature will be added in future updates.

\subsection{Database}

Figure 14 depicts system's database where all of the data is stored in the system. Here, after the registration of a user, the data will be saved in "users" table. When a user chooses a profile as an owner or tenant, the data will shift to the "owner" or "tenant" table. In "post" table, owners advertise about their house will be saved. And at the "comments" table, a discussion between the owner and the tenants about how a house will be saved.

\section{Impact and Sustainability}

The real deal with this system is that cities are growing at an unprecedented rate, presenting a fantastic opportunity for local economic development. However, their residents need good, affordable housing and this remains a challenge in the city. Well-functioning property markets can act as a financial springboard for enterprises and job creation. An enabling environment for affordable housing is often developed with the proper infrastructure, investment and macroeconomic policies targeted towards social and financial inclusion [27].

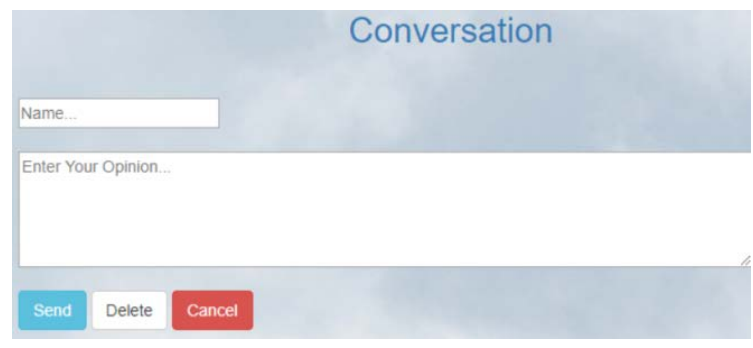

Figure 12. Conversation system.

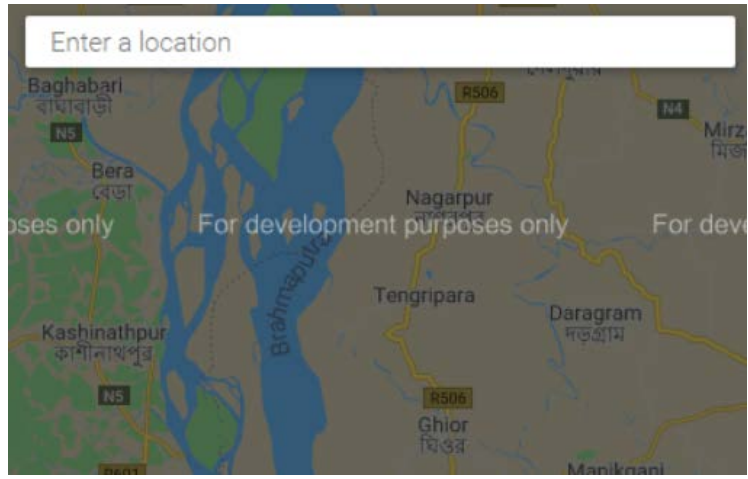

Figure 13. Google map.

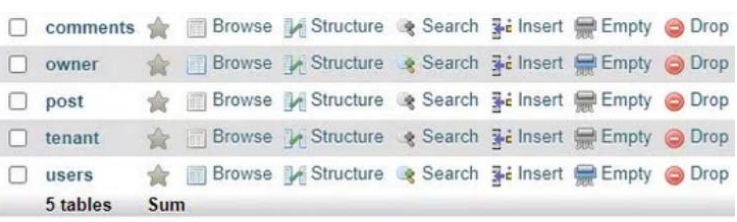

Figure 14. Database of the system. 
The system will be sustainable because of the users and their contribution towards this. The upgrade of the system will be done on a time-to-time basis. More features will be added to make the system more efficient and user-friendly. The extent of the affordable housing challenge, however, varies across geographies. The housing market is affected not only by market conditions, but also by socio-political factors, environmental factors and the regulatory landscape of countries and cities. Finding solutions in a particular city requires a broader understanding of what constitutes affordability and the factors that affect it. Ensuring the healthy functioning of the housing market requires actions that address interdependencies on the supply-side while stimulating interventions on the demand-side. In opposition to these trends stands the concept of social architecture as a means of engaging with global phenomena, a discipline that takes cultural and social issues into account and is more in touch with the changes in economic and social structures and environmental problems characterizing the twenty-first century. Architecture understood as a collective endeavor entails a significant participatory component and a project of this kind must enjoy the involvement of all its stakeholders if it is to be implemented effectively and give rise to a democratic space [28].

The money will be earned by the advertiser. Ads are the main resource of this system. Advertisements will be posted by house owners in exchange for a fee. The money will be spent on the maintenance of the system and on honorariums for the developers. Target users are students, corporate job holders, house owners, house renters. Basically, the user class will be the person who needs to save time by using this system.

\section{Conclusion}

Development of an online web based smart house renting system has been developed in this paper. The system can provide a framework that allows managers to conduct reasonable transactions within a limited time frame. This system is meant to satisfy the needs of rental house owners. Several user-friendly interfaces have also been adopted. The real time chat system will bring fluidity over the usage and connection between owner and tenants. Also, the location tracing system will be a major advantage for users as it will be easy to find the location of the house on a map. In addition, for the concern of security, this system has optimized secure and private data storage and verification system. This package will prove to be very powerful in satisfying all the requirements of the users [29].

\section{Acknowledgements}

Firstly, we would like to express our sincere gratitude to the advisor Dr. Mohammad Monirujjaman Khan for the continuous support, for his patience, motivation, and immense knowledge. We would like to give special thanks to the Department of Electrical and Computer Engineering of North South University to give us opportunities and support to do research on house rent system. 


\section{Conflicts of Interest}

The authors declare no conflicts of interest regarding the publication of this paper.

\section{References}

[1] Trasad, A. (2016) Mundrisoft. https://mundrisoft.com/tech-bytes/flowchart-in-software-engineering-testing

[2] Real Estate and Housing Association of Bangladesh (REHAB) (2004) Annual Report.

[3] Sharma, L. (2017) Toolsqa. https://www.toolsqa.com/software-testing/waterfall-model

[4] Flat Rent in Dhaka. bdhousing. https://www.bdhousing.com

[5] Taipalus, K. (2006) A Global House Price Bubble? Evaluation Based on a New Rent-Price Approach. Bank of Finland Research Discussion, Paper No. 29/2006, 68. https://doi.org/10.2139/ssrn.1018329

[6] Alchian, B.A.-K. (1973) On a Correct Measure of Inflation. Journal of Money, Credit and Banking, 5, 173-191. https://doi.org/10.2307/1991070

[7] Zhu, H. (1983) Rent Increases Linked to CPI. 1985-1987: Indexation Temporarily Suspended. 1991: Freely Negotiated New Rental Fixed Term Contracts Introduced. 1997: Limits Set to New Short-Term Agreements. Freely Negotiated Rents in New Contracts. Minimum Duration of Contracts of Three Years, 27-28.

[8] Bristi, W.R., Chowdhury, F. and Sharmin, S. (2019) Stable Matching between House Owner and Tenant for Developing Countries. 201910 th International Conference on Computing, Communication and Networking Technologies (ICCCNT), Kanpur, 6-8 July 2019, 1-6. https://doi.org/10.1109/ICCCNT45670.2019.8944625

[9] Juha Kilponen, A.R. (2007) Labour and Product Market Competition in a Small Open Economy-Simulation Results Using a DGE Model of the Finnish Economy. Bank of Finland Research Discussion, Paper No. 5/2006, 54, 30 Aug. https://doi.org/10.2139/ssrn.1010631

[10] Gommans, H.P., Njiru, G.M. and Owange, A.N. (2014) Rental House Management System. International Journal of Scientific and Research Publications, 4, 1-24.

[11] Shriram, R.B., Nandhakumar, P., Revathy, N. and Kavitha, V. (2019) House (Individual House/Apartment) Rental Management System. International Journal for Computer Science and Mobile Computing, 19, 143.

[12] Nandhini, R., Mounika, K., Muthu Subhashini, S. and Suganthi, S. (2018) Rental Home System for Nearest Place. International Journal of Pure and Applied Mathematics, 19, 1681.

[13] The Writing Center. https://writingcenter.unc.edu/tips-and-tools/conference-papers

[14] Khan, F. (2011) Rental Housing. United Nations Human Settlements Programme.

[15] Kamila Sommer, P.S.R.V. (2011) Run-Up in the House Price-Rent Ratio: How Much?

[16] Morris, A.L.R.F.M. and Davis, A. (2008) The Rent Price Ratio for the Aggregate Stock of Owne-Occupied Housing.

[17] Alakeson, V. (2011) Making a Rented House a Home: Housing Solutions for "Generation Rent". Resolution Foundation, London, 4-42.

https://www.emcouncils.gov.uk/write/documents/resolution\%20foundation\%20hou sing_report_final.pdf 
[18] Ezebilo, E.E. (2017) Evaluation of House Rent Prices and Their Affordability in Port Moresby, Papua New Guinea. Buildings, 7, 114.

https://www.researchgate.net/publication/321502634_Evaluation_of_House_Rent_ Prices_and_Their_Affordability_in_Port_Moresby_Papua_New_Guinea https://doi.org/10.3390/buildings7040114

[19] Sharmeen, F. (2007) Modeling Urban House-Rent Variation in Bangladesh: A Study of Four Metropolitan Cities.

http://lib.buet.ac.bd:8080/xmlui/handle/123456789/1699

[20] Khanam, S. (2004) Increasing Access to Housing for Low Income People in Bangladesh through Income and Employment Generation. Access to Services Program of ITDG, Volume 12, 2004-09-17.

[21] Talukder, D. (2014) Assessing Determinants of Income of Rural Households in Bangladesh: A Regression Analysis. Journal of Applied Economics and Business Research, 4, 80-106.

[22] Barua, S. and Khan, M.S. (2009) The Dynamics of Residential Real Estate Sector in Bangladesh: Challenges Faced and Policies Sought. Journal of Management Studies, 1,1 .

[23] Hoek-Smit, M.C. (1998) Housing Finance in Bangladesh: Improving Access to Housing Finance by Middle and Lower Income Groups. Prepared for the Government of Bangladesh, Ministry of Local Government, Rural Development and Co-Operatives and UNDP/UNCHS Habitat, Dhaka, 1998-12.

[24] Karnad, R.S. (2004) Housing Finance and the Economy: Regional Trends. South Asia Perspectives. 25th World Congress for International Union for Housing Finance, Brussels, 23 June 2004, 239-253.

[25] Islam, A.H.M.S. (2008) Operations of Bangladesh Housing Industry: An Uncertain Supply Chain Model. The AIUB Journal of Business and Economics (AJBE), 7, 20-31.

[26] Barua, S., et al. (2010) Housing Real Estate Sector in Bangladesh Present Status and Policies Implications. ASA University Review, 4, 239-253.

https://center4affordablehousing.org/wp-content/uploads/2019/01/Housing-Real-E state-Sector-in-Bangladesh-Present-Status-and-Policies-Implications.pdf

[27] Sarker, R., et al. (2008) Real Estate Financing in Bangladesh: Problems, Programs, and Prospects. AIUB Journal of Business and Economics, 7, 78-84.

https://www.academia.edu/1559226/Real_Estate_Financing_in_Bangladesh_Proble ms_Programs_and_Prospects

[28] Al-Nahdi, S., et al. (2015) Factors Influencing the Intention to Purchase Real Estate in Saudi Arabia: Moderating Effect of Demographic Citizenship. International Journal of Business and Management, 10, 35-48.

https://doi.org/10.5539/ijbm.v10n4p35

[29] Benjamin, D.J. (2003) The Environment and Performance of Real Estate. Journal of Real Estate Literature, 11, 279-324. https://doi.org/10.1080/10835547.2003.12090130 